\title{
AS MUDANÇAS CLIMÁTICAS COMO CATÁSTROFE GLOBAL E O REFUGIADO AMBIENTAL
}

\section{CLIMATE CHANGES AS GLOBAL CATASTROPHE AND THE GLOBAL REFUGEE}

SIDNEY GUERRA ${ }^{1}$

\begin{abstract}
RESUMO: A proteção do meio ambiente passou a ter relevância no sistema internacional a partir do momento em que a degradação ambiental atingiu números alarmantes e a sociedade passou a ter consciência de que a preservação do meio ambiente sadio está intimamente ligada à preservação da vida presente e futura. A proposta do presente estudo é apresentar as mudanças climáticas como a principal ameaça global, na perspectiva de possíveis cenários de catástrofes, para ao final acentuar a necessária observância por parte do direito sobre o reconhecimento da figura do refugiado ambiental.
\end{abstract}

Palavras-Chave: Mudanças Climáticas; Direito Internacional Ambiental; Catástrofes.

ABSTRACT: Environmental protection became relevant in the international system from the moment that environmental degradation reached alarming numbers and society became aware that the preservation of a healthy environment is closely linked to the preservation of present and future life. This study proposes to present climate change as the main global threat, in the perspective of possible scenarios of catastrophes, in order to finally emphasize the necessary observance by the law on the recognition of the figure of the environmental refugee.

KEYwORDS: Climate Changes; Environmental International Law; Catastrophes.

\footnotetext{
${ }^{1}$ Pós-Doutor em Direitos Humanos pelo Centro de Estudos Sociais da Universidade de Coimbra. Pós-Doutor pelo Programa Avançado em Cultura Contemporânea da Universidade Federal do Rio de Janeiro (UFRJ). Pós-Doutor em Direito pela Universidade Presbiteriana Mackenzie (UPM). Doutor e Mestre em Direito (UGF). Professor permanente do Programa de PósGraduação em Direito da Universidade Federal do Rio de Janeiro (PPGD/UFRJ), professor convidado do Programa de Pós-Graduação em Direito Internacional da Universidade do Estado do Rio de Janeiro (PPGD/UERJ), professor titular da Universidade do Grande Rio (Unigranrio) e professor visitante da Stetson University Law School. Coordenador do Laboratório de Estudos e Pesquisas Avançadas em Direito Internacional Ambiental (LEPADIA). Advogado. E-mail: sidneyguerra@terra.com.br.
} 


\section{INTRODUÇÃO}

A proteção do meio ambiente passou a ter relevância no sistema internacional a partir do momento que a degradação ambiental atingiu números alarmantes e a sociedade a ter consciência de que a preservação do meio ambiente sadio está intimamente ligada à preservação da vida presente e futura. ${ }^{2}$

Os problemas ambientais ultrapassam os limites territoriais dos Estados nacionais e, portanto, necessárias ações conjuntas no âmbito da sociedade internacional. Conforme assinalado em outro estudo ${ }^{3}$, o Direito Internacional tem um grande objetivo: o ambiente planetário está ameaçado e o direito deve vir em seu socorro. Portanto, sistemas de prevenção ou de reparação adaptados a uma melhor defesa contra as agressões da sociedade moderna devem ser pensados e criados.

No momento atual, o impacto negativo produzido pelas mudanças climáticas apresenta-se como uma das maiores preocupações da humanidade, uma vez que seus efeitos alcançam todo o planeta, com diversos desdobramentos.

Neste cenário de catástrofe ${ }^{4}$ decorrente das mudanças climáticas, o deslocamento de pessoas (migrações) tem impactado diretamente as relações internacionais, o que enseja o aparecimento de nova categoria de indivíduos que buscam refúgio em razão de questões ambientais.

A proposta do presente estudo é apresentar as mudanças climáticas como a principal ameaça global, na perspectiva de possíveis cenários de catástrofes, para ao final acentuar a necessária observância por parte do direito sobre o reconhecimento da figura do refugiado ambiental.

\section{MUdANÇAS CLIMÁticAS: DESASTRES OU CATÁSTROFES?}

De acordo com o relatório da ONU de 2020, "The Human cost of disasters: an overview of the last 20 years (2000-2019) $)^{5 "}$, elaborado pelo Escritório das Nações Unidas para Redução do Risco de Desastres, as mudanças climáticas quase dobraram a ocorrência de desastres naturais nos últimos vinte anos. Ainda em conformidade com o relatório, ao menos 7.348 desastres naturais ocorreram

2 GUERRA, Sidney. Direito internacional ambiental. Rio de Janeiro: Freitas Bastos, 2006.

${ }^{3}$ GUERRA, Sidney. Curso de Direito Internacional Público. 13.ed. São Paulo: Saraiva Educação, 2021, p. 659.

${ }^{4}$ GUERRA, Sidney. Direito Internacional das Catástrofes. 1. Ed. Curitiba. Editora Instituto Memória, 2021.

${ }^{5}$ NACIONES UNIDAS. Human Cost of Disasters: An overview of the last 20 years: 2000-2019.

United Nations Office for Disaster Risk Reduction. Octuber 2020. https://dds.cepal.org/redesoc/publication?id=5361\#: :text=In\%20the\%20period\%202000\%20to,ov er\%20the\%20previous\%20twenty\%20years. Acesso em: 02 julho 2021. 
entre os anos 2000 e 2019, o que resultou na perda de 1,23 milhão de vidas e afetou 4,2 bilhões de pessoas, além de custar à economia global em torno de 2,97 trilhões de dólares (aproximadamente 16,4 trilhões de reais).

Impende assinalar que o estudo apontou que grande parte decorreu do aumento significativo no número de desastres relacionados ao clima, porém, o levantamento relaciona-se apenas para desastres que envolvem perigos naturais, excluindo desastres biológicos e tecnológicos, ou seja, aqueles decorrentes das ações humanas.

Figura 1: Disaster Impacts 1980-1999 vs 2000-2019

Figure 1

Disaster Impacts:

$1980-1999$ vs. $2000-2019$ number or peopie arrectea dy aısasters, inciuaing injuries and disruption of livelihoods, especially in agriculture, and the associated economic damage are growing in contrast to the decrease in mortality.

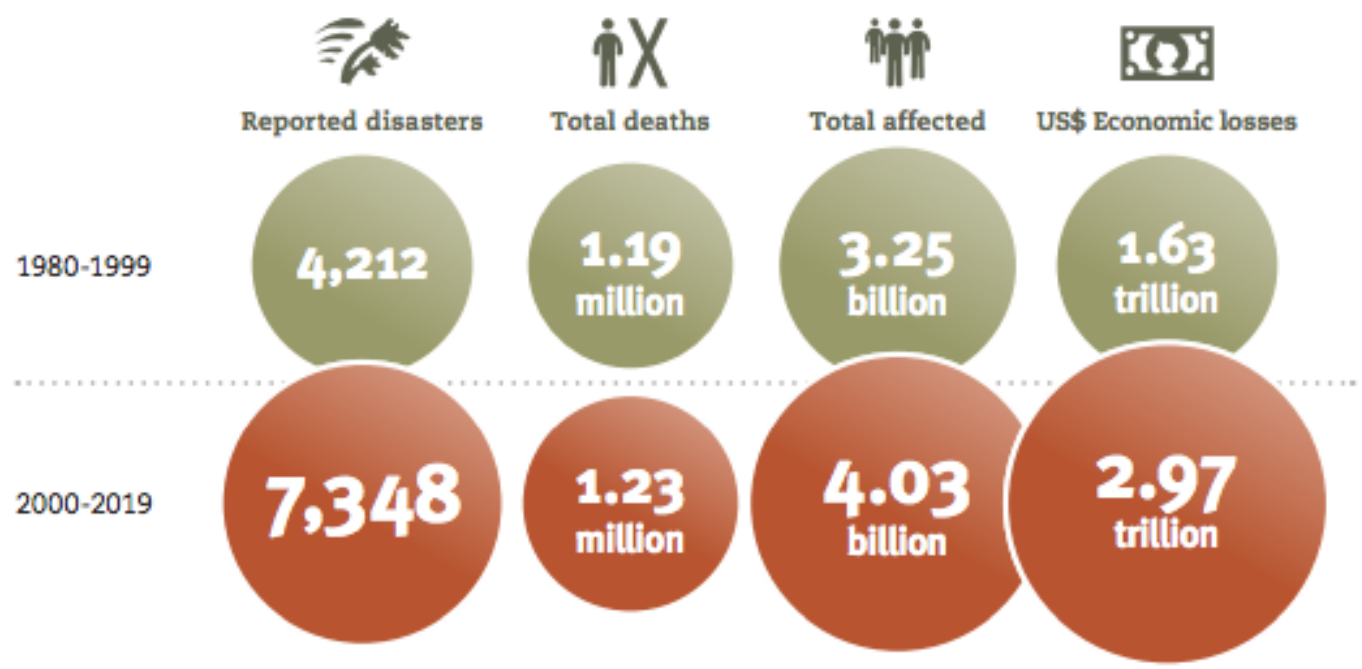

Fonte: Naciones Unidas. Human cost of disasters: an overview of the last 20 years, p. 5

Segundo a pesquisa realizda pelo Pew Research Center, a mudança climática é vista por mais países como a maior ameaça global, embora também sejam apresentadas outras, conforme abaixo ${ }^{6}$. Na metodologia adotada, foram entrevistados 27.612 (vinte e sete mil seiscentos e doze) pessoas que apontaram quais as maiores ameaças que se apresentam na arena internacional: mudanças

\footnotetext{
${ }^{6}$ POUSHTER, Jacob; HUANG, Christine. Climate change still seen as the top global threat, but cyberattacks a rising concern. Pew Research Center, v. 10, 2019, p. 2. Disponível em: https://www.pewresearch.org/global/2019/02/10/climate-change-still-seen-as-the-top-globalthreat-but-cyberattacks-a-rising-concern/. Acesso em: 04 jul. 2021.
} 
climáticas, ataques terroristas por grupos radicais islâmicos; ataques cibernéticos e a influência da Rússia, como se vê7:

Figura 2: Top global threats

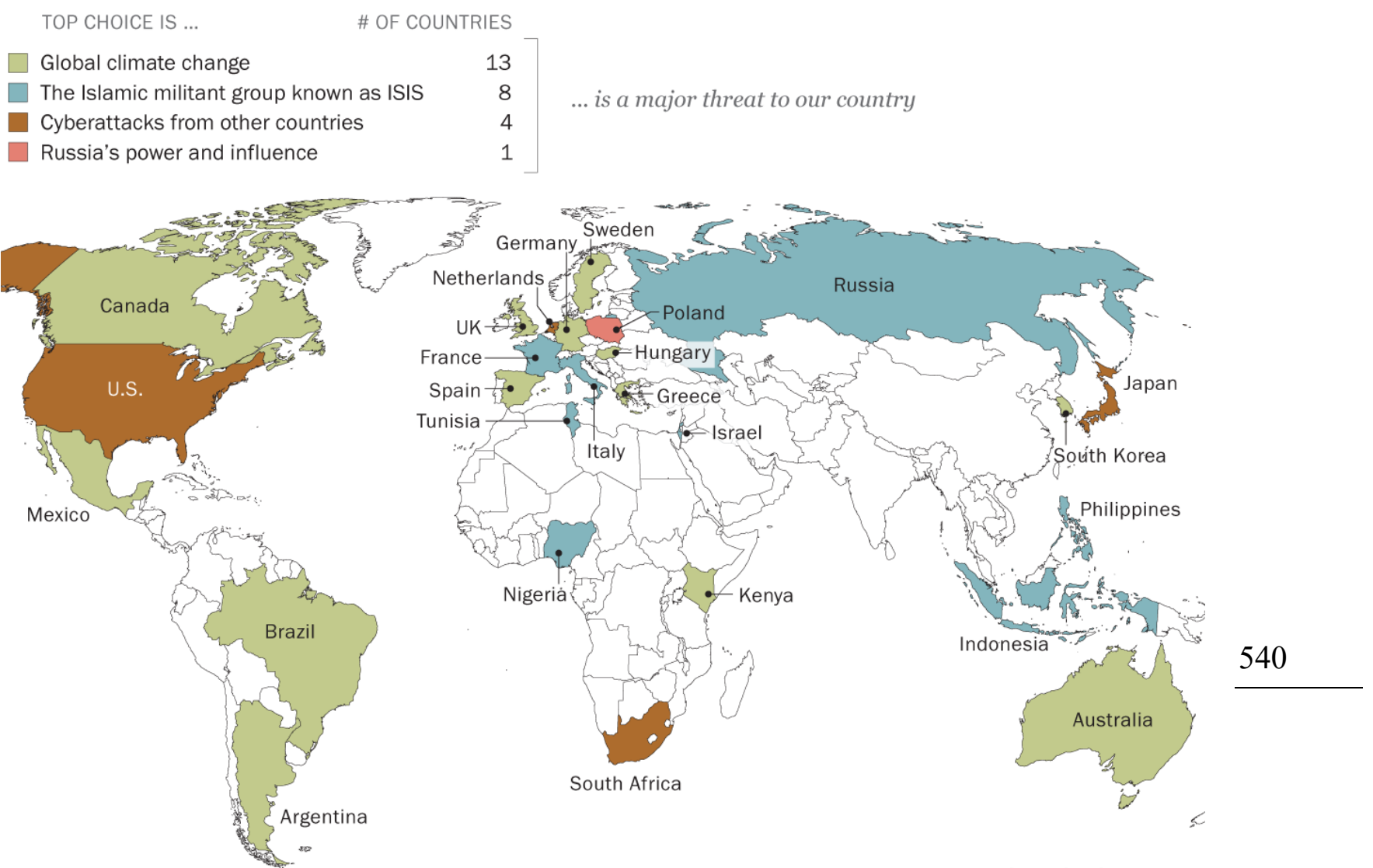

PEW RESEARCH CENTER

Fonte: POUSHTER; HUANG. Climate change still seen as the top global threat, but cyberattacks a rising concern, p. 5

Frise-se, por oportuno, a tomada de consciência da sociedade em torno do tema, conforme consta na pesquisa citada, visto que em 2013, antes do Acordo de Paris ser assinado, 56\% dos indivíduos de 23 países pesquisados, em média, afirmaram que a mudança climática global era a maior ameaça ao seu país. Este índice subiu para 63\% em 2017, e em 2018 para 67\%. Desde 2013 as preocupações com a ameaça climática aumentaram significativamente em 13 dos países onde os dados são acessíveis. Os maiores aumentos foram na França (até 29 pontos percentuais) e México (até 28 pontos), mas também houve aumentos nos Estados

\footnotetext{
7 Ibidem, 2019, p. 4.
} 
Unidos da América, Reino Unido, Alemanha, Espanha, Quênia, Canadá, África do Sul e Polônia. ${ }^{8}$

Feitas as considerações iniciais relacionadas ao tema, torna-se importante enfatizar, neste momento, que deve ser empregada com destaque a expressão catástrofe. Isso porque, conforme já acentuado ${ }^{9}$, as expressões desastres e catástrofes são utilizadas de maneira indiscriminada. Cita-se, como exemplo do uso aleatório das expressões, o Objetivo n. 13 - Ação contra a Mudança Global do Clima, dos 17 Objetivos do Desenvolvimento Sustentável, que ora menciona desastre, ora catástrofes. ${ }^{10}$

Não é por acaso que os estudos formulados no campo doutrinário jurídico que se propõem a formular uma teoria sobre os desastres, acabam por utilizar de maneira indiscriminada as expressões desastres e catástrofes. Nesse sentido Carvalho, ao promover estudo sobre os desastres ${ }^{11}$ no campo jurídico ambiental, adota a linha acima esposada e utiliza as duas expressões como se retratassem a mesma coisa. ${ }^{12}$

De maneira sintética, pode-se afirmar que a eclosão de um desastre pode se dar a partir de fenômenos naturais ou por ações antrópicas e que numa circunstancia ou noutra, apresentar-se-á como um episódio que produzirá danos severos, bem como prejuízos para uma pessoa ou determinado grupo. ${ }^{13}$

De acordo com a ONU, no documento Draft Articles on the protection of persons in the event of disasters, desastre significa:

(a) "desastre" significa um evento calamitoso ou uma série de eventos resultando em perda generalizada da vida, grande sofrimento humano e angústia, deslocamento em massa, ou material em grande escala ou danos ambientais, perturbando gravemente o funcionamento da sociedade; (tradução livre) ${ }^{14}$

8 Ibidem, 2019, p. 5

9 GUERRA, Sidney. Curso de Direito Internacional Público. 13.ed. São Paulo: Saraiva Educação, 2021, p. 714

10 AGENDA 2030. Os 17 Objetivos de Desenvolvimento Sustentável. Disponível em: http://www.agenda2030.org.br/ods/13/ Acesso em: 7 julho 2021.

${ }^{11}$ O autor Délton Winter possui estudo específico sobre Direito dos Desastres. Vide CARVALHO, Délton Winter de. Desastres ambientais e sua regulação jurídica: deveres de prevenção, resposta e compensação ambiental. São Paulo: Revista dos Tribunais, 2015.

12 GUERRA, Sidney. Direito Internacional das Catástrofes. 1. Ed. Curitiba. Editora Instituto Memória, 2021, cap. 2.

${ }^{13}$ GUERRA, Sidney. Curso de Direito Internacional Público. 13.ed. São Paulo: Saraiva Educação, 2021. Pág. 718.

${ }^{14}$ UNITED NATION. Draft Articles on the protection of persons in the event of disasters. 2016. Disponível em: https://legal.un.org/ilc/texts/instruments/english/draft_articles/6_3_2016.pdf. Acesso em: 02 julho 2021. 
Para que seja possível uma diferenciação de forma clara, faz-se necessário delimitar o que se entende por catástrofes.

Antônio Portela define catástrofe como uma desgraça pública, calamidade, flagelo, na qual pode ter origem em fenômenos naturais, em ações e comportamentos das comunidades humanas ou resultar da conjugação de fenômenos naturais e de ações humanas.

Ricard Posner ${ }^{15}$ desenvolve a identificação e governança de riscos catastróficos que aparecem no século 21. O autor cita como exemplo, os riscos associados ao bioterrorismo, aquecimento global, modificação genética de plantações, perda de biodiversidade, guerra nuclear e entre outros efeitos e experiências imprevistas. Segundo o autor, são eventos que tem baixa probabilidade de se materializar, mas caso se materialize pode causar um grande dano e repentino, por causa do elemento da incerteza.

A eclosão de um desastre pode se dar a partir de fenômenos naturais e por ações antrópicas. E que numa circunstância ou outra serão apresentados episódios que produzirão danos severos e também prejuízos para uma pessoa num determinado grupo. A catástrofe quando confrontada com o desastre, se apresenta num plano muito maior, uma desgraça, uma calamidade, podendo ser produzida por fenômenos naturais ou ações antrópicas. Nesse sentido, um evento que tem baixa probabilidade de materializar, mas caso venha acontecer pode provocar um dano gigantesco e repentino. ${ }^{16}$

Sobre esse efeito e escala, Tanya Gulliver-Garcia também destaca que as terminologias são usadas como sinônimo muitas das vezes, porém, há diferença tanto na escala quanto na suportabilidade:

Não importa o tamanho de um acidente ou desastre, certamente parece uma catástrofe para as pessoas afetadas. Mas catástrofe, conforme usado pelo Center for Disaster Philanthropy, faz referência a um tipo específico de desastre - um que é extremamente grande e está fora da capacidade de enfrentamento de uma comunidade. $\mathrm{O}$ mesmo perigo (incêndio, por exemplo) pode ser um acidente, desastre ou catástrofe, dependendo da escala do impacto. Um incêndio em uma residência familiar é um acidente ou emergência; um incêndio que consome alguns quarteirões da cidade é um desastre; e um incêndio que destrói várias comunidades, exigindo evacuação em massa e reconstrução é uma catástrofe (tradução livre). ${ }^{17}$

${ }_{15}$ POSNER, Richard. Catastrophe: risk and response. Oxford. University Press, USA, 2004.

16 Vide a propósito o estudo de GUERRA, Sidney. Direito Internacional das Catástrofes. 1. Ed. Curitiba. Editora Instituto Memória, 2021, cap. 2

17 CENTER FOR DISASTER PHILANTHROPY. Disaster versus Catastrophes: The Difference Matter. Tanya Gulliver-Garcia. Octuber, 2019. Disponível em: https://disasterphilanthropy.org/blog/hurricanes-typhoons/disasters-versus-catastrophes-thedifference-matters/. Acesso em: 04 junho 2021. 
Destaca-se ainda, de acordo com o National Response Framework - NRF, que um incidente catastrófico é aquele de severidade ou magnitude extrema e notável e possui uma dimensão coletiva, representando potenciais ameaças à segurança nacional, segurança econômica nacional, saúde pública e segurança da nação que demanda posição dos tomadores de decisão para analisar o cenário e gerenciar e priorizar recursos.

De fato, os efeitos de catástrofes atingem a todos, porém, os impactos podem ser diferenciados dependendo da localidade que se atinge e também a duração dos efeitos decorrentes do fato.

Cenários catastróficos demandam maior mobilização, o que pode ocorrer de forma mais rápida em países que possuem mais recursos para a resiliência requerida, ao contrário de países que não possuem ou possuem poucos recursos, como foi no Terremoto no Haiti, em 2010. Outro ponto que deve ser observado é a possibilidade desse acontecimento alcançar outros países ao atravessar fronteiras.

Sem embargo, partindo-se da ideia central de que há uma sociedade de risco e que as ações da natureza e de intervenções humanas produzem diversos efeitos nos cenários de catástrofes, é necessário indicar que o elemento potencializador da catástrofe é o risco.

Outro elemento que se apresenta como conceito chave para compreensão dos riscos de forma integrada e contextualizada é a vulnerabilidade. Este elemento (vulnerabilidade) irá permitir a discussão de seus vários aspectos e que são pertinentes a ética, política e técnicas que irão conformar a distribuição dos riscos na sociedade. ${ }^{18}$

Frise-se, por oportuno, que é possível identificar na Agenda $2030{ }^{19}$ a preocupação com os desastres em diferentes pontos e, em particular, para efeito deste estudo, as mudanças climáticas, como se vê: objetivo 1. Acabar com a pobreza em todas as suas formas, em todos os lugares ${ }^{20}$; objetivo 2. Acabar com a fome, alcançar a segurança alimentar e melhoria da nutrição e promover a agricultura sustentável ${ }^{21}$; objetivo 11 . Tornar as cidades e os assentamentos

18 GUERRA, Sidney. GUERRA, Sérgio. Curso de Direito Ambiental. 2.ed. São Paulo: Atlas, 2014. p.15.

19 ITAMARY. Transformando Nosso Mundo: A Agenda 2030 para o Desenvolvimento Sustentável. 2015.2 Disponível em: http://www.itamaraty.gov.br/images/ed_desenvsust/Agenda2030-completo-site.pdf. Acesso em: 15 julho 2021.

${ }^{20} 1.5$ até 2030, construir a resiliência dos pobres e daqueles em situação de vulnerabilidade, e reduzir a exposição e vulnerabilidade destes a eventos extremos relacionados com o clima e outros choques e desastres econômicos, sociais e ambientais.

${ }^{21} 2.4$ até 2030, garantir sistemas sustentáveis de produção de alimentos e implementar práticas agrícolas robustas, que aumentem a produtividade e a produção, que ajudem a manter os ecossistemas, que fortaleçam a capacidade de adaptação às mudanças do clima, às condições meteorológicas extremas, secas, inundações e outros desastres, e que melhorem progressivamente a qualidade da terra e do solo. 
humanos inclusivos, seguros, resistentes e sustentáveis 22 ; e objetivo 13. Tomar medidas urgentes para combater a mudança do clima e seus impactos. ${ }^{23}$

\section{AS MUDANÇAS CLIMÁTICAS COMO CATÁSTROFE GLOBAL}

A mudança climática apresenta-se como problema inerente as gerações presentes e as futuras. ${ }^{24}$ Segundo Weiss, deve-se reconhecer que as mudanças climáticas globais são causadas em parte por atividades humanas e levantam sérios problemas de justiça entre a nossa geração e, por isso, deve-se respeitar os princípios da equidade intergeracional. ${ }^{25}$

As mudanças climáticas atingem o mundo inteiro, porém, em alguns locais o impacto ocorre de forma mais intensa ou o próprio país possui uma capacidade de resiliência que permite que o local se recupere de forma mais rápida.

Segundo McAdam ${ }^{26}$, a região Ásia-Pacífico é uma das mais atingidas pelo desequilíbrio ambiental e mudanças climáticas, o que enseja deslocamento de grande contingente populacional. Não por acaso, esta região foi responsável por concentrar mais de $80 \%$ dos deslocamentos no período entre 2008 e 2018, alcançando o relevante número de aproximadamente 187 milhões de pessoas. ${ }^{27}$

A crise ambiental evidencia o consumo exacerbado onde evidencia-se que a sociedade caminha para o esgotamento de recursos naturais, o que paulatinamente compromete a existência do planeta Terra ao passo em que enseja

${ }^{22} 11.5$ até 2030, reduzir significativamente o número de mortes e o número de pessoas afetadas por catástrofes e diminuir substancialmente as perdas econômicas diretas causadas por elas em relação ao produto interno bruto global, incluindo os desastres relacionados à água, com o foco em proteger os pobres e as pessoas em situação de vulnerabilidade.

11.b até 2020, aumentar substancialmente o número de cidades e assentamentos humanos adotando e implementando políticas e planos integrados para a inclusão, a eficiência dos recursos, mitigação e adaptação à mudança do clima, a resiliência a desastres; e desenvolver e implementar, de acordo com o Marco de Sendai para a Redução do Risco de Desastres 20152030, o gerenciamento holístico do risco de desastres em todos os níveis.

${ }^{23} 13.1$ reforçar a resiliência e a capacidade de adaptação a riscos relacionados ao clima e às catástrofes naturais em todos os países.

${ }^{24}$ Tradução livre. WEISS, E.B. Climate chance, intergenerational equity and international law. Vermont Journal Environmental Law. 2008. n.9, p.615.

${ }^{25}$ Tradução livre. WEISS, E.B. Climate chance, intergenerational equity and international law. Vermont Journal Environmental Law. 2008.

${ }^{26}$ MCADAM, Jane; PRYKE, Jonathan. Mudança Climática, Desastres e Mobilidade: Um Roteiro para a Ação Australiana. 2020, p. 400 Disponível em https://www.kaldorcentre.unsw.edu.au/publication/podcast-climate-change-disasters-andmobility-roadmap-australian-action. Acesso em: 20 julho. 2021.

${ }^{27}$ MCADAM, Jane; PRYKE, Jonathan. Mudança Climática, Desastres e Mobilidade: Um Roteiro para a $\begin{array}{llllcll}\text { Ação Australiana. } & 2020, & \text { p. } & 8 & \text { Disponível em }\end{array}$ https://www.kaldorcentre.unsw.edu.au/publication/podcast-climate-change-disasters-andmobility-roadmap-australian-action. Acesso em: 20 julho. 2021. 
a proliferação de crescentes problemas ambientais e de saúde pública. Sem dúvidas, os limites da suportabilidade natural do planeta estão sendo ultrapassados ${ }^{28}$ e produzem sérios prejuízos nos campos econômicos, éticos, político e social.

Como exposto, a insustentabilidade dos padrões comportamentais e de consumo humano consolidam-se enquanto ameaças notáveis ao meio ambiente, $\mathrm{e}$ por essa razão têm se tornado importante foco de discussão da sociedade internacional.

A preocupação com as alterações climáticas e seus impactos na vida humana e no ambiente é assunto de política internacional com diversos foros, debates entre outros. A constante intensificação de eventos como enchentes e inundações, desflorestamentos, queimadas e consequentes emissão de gases poluentes, dentre outros fenômenos, preocupam as mais diversas nações, e, por isso, estas têm se esforçado para compreender a atual conjuntura ambiental e mitigar efeitos danosos. Por isso, já foram elaborados vários documentos que retratam a gravidade e complexidade da temática. As mudanças climáticas estão entre os riscos globais mais comentados e investigados. ${ }^{29}$

David Frame e Myles R. Allen alertam para a mudança climática catastrófica, ao tratarem inicialmente da posição científica (e política) dominante e abordagens que envolvem as discussões sobre os impactos e o conceito de "interferência antropogênica perigosa" no sistema climático.

Dada a sua importância, vários estudos científicos são apresentados que reforçam a urgência para adotar medidas que desacelere a processo de degradação ambiental.

Neste sentido, pode ser destacado o produzido pela equipe multidisciplinar de pesquisadores no Intergovernamental Panel on Climate Change (IPCC), criada em 1988, que tem desempenhado papel importante na avaliação científica do clima. Neste estudo demonstra-se a realidade da mudança climática antropogénica com dados científicos que contemplam seus impactos e riscos futuros e respostas de políticas públicas sobre o tema. Todos esses dados são importantes para auxiliar na condução das negociações internacionais e para o regime das mudanças climáticas.

Sem embargo, há diversos casos e exemplos de catástrofes ambientais que podem ser assinaladas neste mister, como as cheias enfrentadas pelo estado amazonense, onde a região norte do Brasil enfrenta desde o início de 2021 chuvas acima da média, o que influencia diretamente nas graves inundações ao longo das bacias dos rios Negro e Solimões. ${ }^{30}$

${ }^{28}$ GUERRA, Sidney, Direito Internacional Ambiental. Rio de Janeiro: Atlas, 2006.

${ }^{29}$ NICK, FRAME. David. ALLEN. Climate change and global risk. In: Global Catastophic Risks. BOSTROM, Nick; ĆIRKOVIĆ (Org.) Orford. New York: Orford University Press. 2008. P. 538

${ }^{30}$ AUGUSTO, Lukas. Amazonas deve registrar cheias severas em 2021, diz serviço geológico: alerta vale para Manaus, Manacapuru e Itacoatiara. Agência Brasil. Brasília, p. 1-1. 05 abr. 2021. 
Eventos recentes pelo mundo também comprovam a crise climática, como por exemplo, as Catástrofes na China e na Alemanha. ${ }^{31}$ No primeiro caso, deixaram pelo menos 25 mortes, interrupção dos serviços de ônibus na cidade de 12 milhões de habitantes, mais de 500 pessoas resgatadas do metrô inundado. Tal caso foi considerado pelas autoridades meteorológicas como a pior chuva em mil anos. ${ }^{32}$ Outro episódio importante, nos últimos dias, relaciona-se a enchente na Alemanha que inundou cidades inteiras. ${ }^{33}$

Com efeito, o ano de 2021 deve ser o ano para a ação climática - "o ano do sucesso ou do fracasso", conforme mencionou o Secretário-geral das Nações Unidas, António Guterres, no lançamento do relatório da Organização Meteorológica Mundial (OMM) sobre o estado do clima global 2020, que destacou indicadores de mudança climática acelerados e impactos agravantes. ${ }^{34}$ Ele destacou que o "relatório mostra que 2020 também foi outro ano sem precedentes de climas extremos e desastres climáticos. A causa é clara. Mudança climática antropogênica - perturbação climática causada por atividades humanas, decisões humanas e loucura humana", disse ele.

Guteress listou uma série de avanços concretos na preparação para as negociações sobre Mudança Climática da ONU, COP-26, em Glasgow em novembro 35 :

“a) Uma coalizão global comprometida com emissões líquidas zero - para cobrir todos os países, cidades, regiões, empresas e instituições financeiras. b) os próximos 10 anos precisam ser uma década de transformação, com contribuições mais ambiciosas, determinadas nacionalmente, e planos climáticos no âmbito do

Disponível em: https://agenciabrasil.ebc.com.br/geral/noticia/2021-04/amazonas-deve-registrarcheias-severas-em-2021-diz-servico-geologico. Acesso em: 16 abr. 2021.

31 UOL INTERNACIONAL. Catástrofes na China e na Alemanha confirmam gravidade da crise climática Julho. 2021. Disponível em: https://noticias.uol.com.br/ultimasnoticias/rfi/2021/07/22/catastrofes-na-china-e-na-alemanha-confirmam-avanco-e-gravidade-dacrise-climatica.htm. Acesso em: 20 julho. 2021.

32 AGÊNCIA BRASIL. Pior chuva em mil anos deixa pelo menos 25 mortos em província chinesa. Julho. 2021. Disponível em: https://agenciabrasil.ebc.com.br/internacional/noticia/2021-07/piorchuva-em-mil-anos-deixa-pelo-menos-25-mortos-em-provincia-chinesa Acesso em: 20 julho. 2021.

${ }^{33}$ DW. COM. Inundações na Alemanha: Antes e depois da catástrofe. Julho. 2021. Disponível em: https://www.dw.com/pt-002/inunda\%C3\%A7\%C3\%B5es-na-alemanha-antes-e-depois-dacat\%C3\%A1strofe/a-58319862. Acesso em: 20 julho. 2021.

${ }^{34}$ WORLD METEOROLOGICAL ORGANIZATION. 2021 is "Make or break year"for Climate Action" Disponível em: https://public.wmo.int/en/media/news/2021-\%E2\%80\%9Cmake-orbreak-year\%E2\%80\%9D-climate-action. Acesso em: 20 julho. 2021.

${ }^{35}$ WORLD METEOROLOGICAL ORGANIZATION. 2021 is "Make or break year"for Climate Action" Disponível em: https://public.wmo.int/en/media/news/2021-\%E2\%80\%9Cmake-orbreak-year\%E2\%80\%9D-climate-action. Acesso em: 20 julho. 2021. 
Acordo de Paris; c) esses compromissos devem ser respaldados por ações imediatas e concretas; os trilhões de dólares gastos na recuperação do COVID-19 devem estar alinhados com o Acordo de Paris e os Objetivos de Desenvolvimento Sustentável; d) os subsídios aos combustíveis fósseis poluentes devem ser transferidos para as energias renováveis. $\mathrm{E}$ os países desenvolvidos devem liderar a eliminação gradual do carvão - até 2030 nos países da OCDE e 2040 em outros lugares."

O relatório apresenta os principais indicadores climáticos, com as concentrações recordes de gases do efeito estufa, o aumento das temperaturas da terra e do oceano, aumento do nível do mar, derretimento do gelo e condições meteorológicas extremas. Outro ponto interessante são os impactos no desenvolvimento socioeconômico, pobreza, escassez de água, migração e deslocamento, conflitos, segurança alimentar e perda de ecossistemas terrestres e marinhos. ${ }^{36}$

Figura 3: Global annual mean temperatyre difference from pre-industrial conditions (1850-1900) for five global temperature data sets .
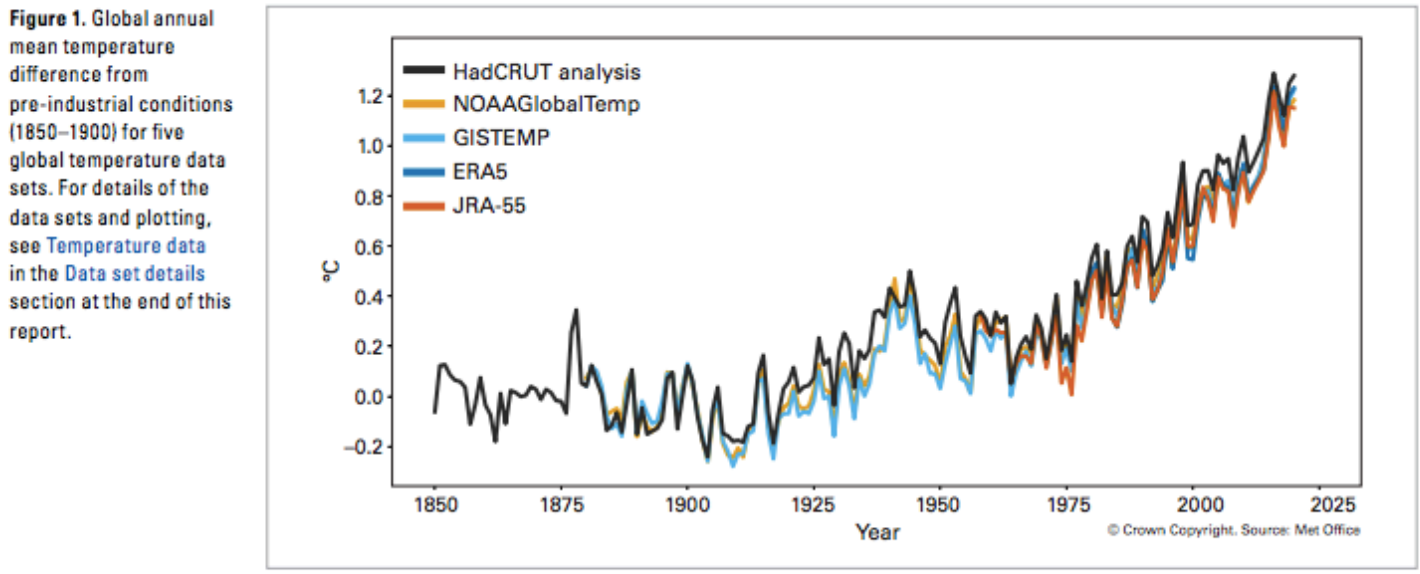

\footnotetext{
https://journals.ametsoc.org/view/journals/bams/aop/bamsD190196/bamsD190196.xml ${ }^{2}$ http://www.ipcc.ch/sr15/
}

Fonte: World Meteorological Organization. State of the Global Climate, p. 6

36 WORLD METEOROLOGICAL ORGANIZATION. State of the Global Climate 2020. 2021. Disponível em: https://library.wmo.int/doc_num.php?explnum_id=10618. Acesso em: 20 julho. 2021. 
Figura 4: Selected climate chanfe-related risks to the achievement of the SDGs

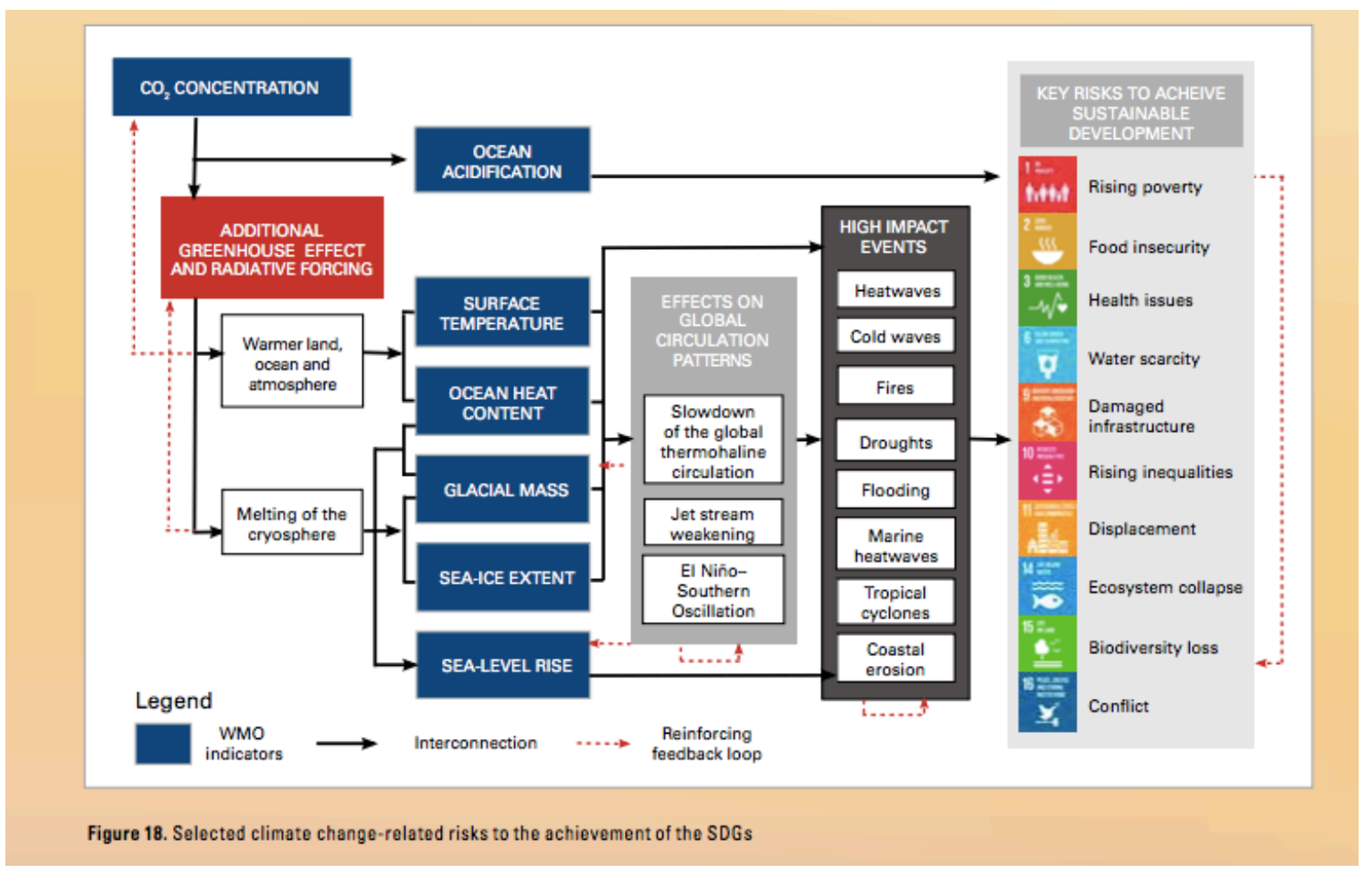

Fonte: World Meteorological Organization. State of the Global Climate, p. 31

Nesse sentido, ganha destaque neste estudo a questão dos deslocamentos em razão de mudanças climáticas que corresponde ao tema do refugiado ambiental. Evidencia-se que parcela populacional será a menos habilitada para adaptar-se às mudanças ambientais. Os que são privados da base econômica para sua existência migrarão da zona de miséria e o êxodo de refugiados ambientais e climáticos ${ }^{37}$ irão procurar abrigo nos países mais desenvolvidos; as crises nos

${ }^{37}$ Vide a propósito o Relatório Global sobre Riscos de 2020, p. 34/38: “Climate realities The nearterm consequences of climate change add up to a "planetary emergency". Implications are catastrophic, wide-ranging and intersecting. Worse still, the complexity of the climate system means that some impacts are still unknown. Established risks include: 1) Loss of life - More and more species are becoming extinct. Humans, too, will experience loss of life- but potentially unequally. Women and children are 14 times more likely than men to die during natural disasters, which are likely to intensify or become more frequent because of climate change. The elderly and infirm are also at higher risk. Climate change will also lead to increased health spillovers, burdening already stretched health systems, particularly for the poorest and most vulnerable, including in many low- and middle-income countries. 2) Stress on ecosystems Oceans are getting warmer, stormier and more acidic, impacting the health of sensitive marine ecosystems such as coral reefs. As glaciers and ice sheets melt, low-lying geographies will flood;14 indeed, by 2050, three times more people will be impacted than previously thought. This risk was explored in detail in the 2019 Global Risks Report chapter Fight or Flight, which 
examined the intersection of rapid urbanization and rising sea levels. Additionally, a scenario in which ice-cap melt creates disruption to the Gulf Stream could cause further ecosystem disorder, as well as major change in the pattern of severe weather perils. Another significant unknown risk relates to the potential thawing of permafrost-frozen soil around the poles that stores nearly twice as much carbon as the atmosphere currently holds. If the soil thaws, this carbon could be released with unprecedented consequences. 3) Food and water crises - Crop yields will likely drop in many regions, undermining the ability to double food production by 2050 to meet rising demand. Because agriculture, livestock and deforestation produce nearly a quarter of global emissions, more efficient use of land is critical; it's also one of the best potential carbon sequestration options. Water scarcity will increase as well-it already affects a quarter of the world's population. 4) Increased migration - From 2008 to 2016, over 20 million people a year have been forced from their homes by extreme weather such as floods, storms, wildfires and hotter temperatures. Tropical Cyclone Idai, for example, displaced nearly 150,000 people in March 2019. Rising sea levels will increasingly create refugees as people flee low-lying areas. Indeed, defence and intelligence agencies are now regularly warning that climate change could trigger conflicts severe enough to uproot entire populations. Exacerbation of geopolitical tensions. Countries will face more potential points of contention as climate change reshapes the security of and access to historic common property resources, such as fishing waters. Melting sea ice could enable new shipping routes through the Arctic, as well as opportunities for natura resource extraction, all of which could cause tension between countries already at odds over unresolved maritime and land boundaries (see Chapter 1, Global Risks 2020). According to the UN, water was a major factor in conflict in 45 countries in 2017; disputes between upstream and downstream areas will likely intensify. And as transition to a more decentralized, renewable energy economy changes geopolitical equations and creates new vulnerabilities for certain states and regions, states' relative position in the international system will shift as well. 5) Economic impacts - Worldwide economic stress and damage from natural disasters in 2018 totalled US $\$ 165$ billion, and $50 \%$ of that total was uninsured.26 A report by federal agencies suggests that, in the United States alone, climate-related economic damage could reach $10 \%$ of gross domestic product (GDP) by the end of the century. Over 200 of the world's largest firms estimated that climate change would cost them a combined total of nearly US $\$ 1$ trillion in the case of nonaction. At the same time, there is broad recognition among these same firms that there are significant economic opportunities, provided the right strategies are put in place.28 Countries will also experience losses unequally, with the highest economic costs being felt by large economies, while risk of exposure, death and non-economic costs is higher in smaller, poorer economies. 6) Capital market risks - Central banks increasingly see climate change as a systemic risk to the global capital market and recognize that non-action is not an option.30 More common extreme weather events could make insurance unaffordable or simply unavailable for individuals and businesses: globally, the "catastrophe protection gap" - what should be insured but is not-reached US $\$ 280$ billion in 2018. The transition to a low-carbon economy also creates potential challenges that will need to be managed. For example, action to reduce emissions could turn approximately $30 \%$ of current oil reserves, $50 \%$ of gas reserves and $80 \%$ of coal reserves into stranded assets for extractive companies and their investors. Pension funds may face catastrophic shortfalls as industries consolidate and transition. Climate risk may also cause disruption to the mortgage market, particularly in vulnerable regions such as Florida where 30year mortgages could default en masse if homes become uninsurable over time. Disponível em https://www.weforum.org/reports/the-global-risks-report-2020. Acesso em 21/05/2021. 
países então chamados de Terceiro e Quarto mundo poderá culminar em uma guerra. ${ }^{38}$ Oportuno, portanto, indicar algumas considerações sobre os denominados refugiados ambientais.

\section{As CATÁSTROFES AMBIENTAIS E OS REFUGIADOS}

A ocorrência cada vez mais comum de catástrofes ambientais, seja por interferência antrópica ou causas naturais, tem feito com que grupos de pessoas tenham que se deslocar para estabelecer habitação em outros locais.

Embora o fenômeno do deslocamento por motivos ambientais não seja novidade, visto que sempre ocorreu no decorrer da história, hodiernamente tem-se observado uma intensificação desse tipo de fluxo migratório, o que tem ensejado a discussão jurídica a respeito de sua inclusão enquanto categoria.

O termo "refúgio ambiental" foi popularizado em 1985 pelo autor egípcio Essam El- Hinnawi, professor do Egyptian National Research Centre, no Cairo. Englobaria, assim "aquelas pessoas que foram forçadas a abandonar seu habitat tradicional, temporária ou permanentemente, devido a uma grave interrupção ambiental natural ou desencadeada por pessoas, que comprometeram sua existência e afetaram seriamente a qualidade de sua vida. "Interrupção ambiental" significa qualquer mudança física, química ou biológica no ecossistema (ou a base de recursos) que o representam, temporariamente ou permanentemente, impróprios para suportar a vida humana". ${ }^{39}$

A Convenção da ONU de 1951 estabelece as hipóteses e situações consideradas como ensejadoras de refúgio e há uma discussão acerca da existência dos refugiados ambientais enquanto categoria migratória, tendo em vista que não são contemplados na Convenção. ${ }^{40}$

\footnotetext{
${ }^{38}$ No original: The greenhouse effect, for example, will raise temperatures and sea levels around the world as a result of the melting of the polar ice caps. The interGlacial period will submerge entire coastal regions, turn farmland into deserts, shift climate zones in unpredictable ways and dramatically accelerate the extinction of species. The poorest people in the world will be the hardest hit. They will be the least able to adapt themselves to the changes in the environment. But those who are deprived of the basis of their economic existence will flee the zone of misery. An exodus of eco-refugees and climatic asylum seekers will flood across the wealthy North; crises in the so-called Third and Fourth Worlds could escalate into war.

${ }^{39}$ Vide GUERRA, Sidney. Curso de direito internacional público, cap. XXII.

${ }^{40}$ A Convenção relativa ao estatuto dos refugiados de 1951 define refugiado como qualquer pessoa que: "foi considerada refugiada nos termos dos ajustes de 12 de maio de 1926 e de 30 de junho de 1928, ou das Convenções de 28 de outubro de 1933 e de 10 de fevereiro de 1938, além do Protocolo de 14 de setembro de 1939, ou ainda da Constituição da Organização Internacional dos Refugiados; as decisões de inabilitação tomadas pela Organização Internacional dos Refugiados durante o período do seu mandato não constituem obstáculo a que a qualidade de refugiados seja reconhecida a pessoas que preencham as condições previstas no "§ $2 \underline{\underline{o}}$ da presente seção"; em consequência dos acontecimentos ocorridos antes de $1 \underline{\underline{o}}$ de janeiro de 1951 e temendo ser
} 
Nessa lógica, Astri Suhrke destaca que existem duas perspectivas quanto a temática do refugiado ambiental, a minimalista e a maximalista. A primeira, segundo a autora, entende que a degradação ambiental por si só não é um fator determinante para as migrações, estando atrelada a outros fatores, como por exemplo, econômicos e sociais. A segunda, por sua vez, considera a degradação ambiental como causa imediata da migração. ${ }^{41}$

A partir dessas duas perspectivas, podem-se citar autores ${ }^{42}$, que sustentam o uso da terminologia "refugiado ambiental" e outros que entendem não ser cabível.

Nesta esteira Stephen Castles $^{43}$ sustenta a inadequação da noção de refugiado ambiental. Para o autor, a questão central do problema talvez não seja a mudança ambiental, mas a capacidade de diferentes comunidades e países em lidar com isso. Dessa forma, o problema seria principalmente político-social e não ambiental.

José Antônio Tietzmann e Silva, por sua vez, em defesa da existência de uma categoria de migrantes por razões ambientais argumenta que "mesmo que os motivos que tenham ensejado o processo migratório decorram de interesses pessoais, familiares, sociais, condições econômicas etc. das pessoas, desde que haja um motivo preponderante que se vincule à degradação substancial das condições do ambiente em que viviam, estar-se-á diante de migrantes

perseguida por motivos de raça, religião, nacionalidade, grupo social ou opiniões políticas, encontra-se fora do país de sua nacionalidade e que não pode ou, em virtude desse temor, não quer valer--se da proteção desse país, ou que, se não tem nacionalidade e se encontra fora do país no qual tinha sua residência habitual em consequência de tais acontecimentos, não pode ou, devido ao referido temor, não quer voltar a ele; no caso de uma pessoa que tem mais de uma nacionalidade, a expressão "do país de sua nacionalidade" refere-se a cada um dos países dos quais ela é nacional. Uma pessoa que, sem razão válida fundada sobre um temor justificado, não se houver valido da proteção de um dos países de que é nacional, não será considerada privada da proteção do país de sua nacionalidade.

${ }^{41}$ SUHRKE, Astri. Pressure Points: Environmental Degradation, Migration and Conflict. 1993. p 4-6. Disponível em: < https://www.cmi.no/publications/file/1374\%20pressure-points-environmentaldegradation.pdf> Acesso em: 29 de setembro de 2017.

${ }^{42}$ GUERRA, Sidney. O refugiado à luz do direito internacional ambiental, artigo publicado na Ius gentium (Facinter), v. 6, 2009. O direito internacional e a figura do refugiado ambiental: reflexões a partir da ilha de Tuvalu, artigo publicado nos Anais do XVII Congresso Nacional do CONPEDI, Brasília, 2008.

${ }^{43}$ CASTLES, Stephen. "Environmental change and forced migration: making sense of the debate." UNHCR. 2002, p.5. Disponível em: http://www.unhcr.org/research/working/3de344fd9/environmental-change-forced-migrationmaking-sense-debate-stephen-castles.html> Acesso em: 29 de set. de 2017. 
ambientais." 44

Assim, ainda que existam outros fatores, prevalecendo razões ambientais, a existência dessa categoria não deve ser desconsiderada. Alguns autores ${ }^{45}$ defendem essa categorização, tendo em conta que a Convenção preceitua o conceito de refugiados para os fins daquela Convenção. Logo, segundo o seu entendimento, não deve haver óbice ao uso do termo refugiado em outro contexto. Esses indivíduos seriam, então, refugiados não convencionais dado que são refugiados, mas não se encontram entre os preceituados pela Convenção da ONU.

A respeito dessa controvérsia existente quanto a melhor denominação, Álvaro Mirra ${ }^{46}$ explica que duas estratégias são pensadas sob o enfoque do direito internacional. A primeira delas é a modificação de instrumentos convencionais já existentes, como a já mencionada convenção da ONU. A segunda estratégia, é elaborar uma nova convenção internacional específica sobre o assunto. Nesse sentido, aponta que existe um Projeto de Convenção Internacional sobre o Estatuto Internacional dos Deslocados Ambientais ${ }^{47}$, elaborado por um grupo de juristas do direito ambiental e direitos humanos ligados à Universidade de Limoges, na França.

Assim, seria consagrado um estatuto jurídico específico para os deslocados ambientais, não se restringindo em âmbito regional, mas disponível a adoção de todos os países.

Quanto ao uso da expressão refúgio, Carolina Claro esclarece que o termo é oriundo de refugiare, que tem o sentido de buscar abrigo ou proteção, não sendo razoável, deste modo, ter emprego exclusivo de um tratado internacional que, ainda que essencial a temática a qual se refira, restringe a proteção a situações específicas de outra conjuntura, que envolve aspectos históricos, políticos e sociais diferentes.

${ }^{4}$ SILVA, José Antônio Tietzmann. "Os refugiados ambientais à luz da proteção internacional dos direitos humanos". Revista dos Tribunais. Vol 86, 2017.

${ }^{45}$ CLARO, Carolina. "A proteção dos "Refugiados Ambientais" no Direito Internacional." Faculdade de Direito da Universidade de São Paulo. 2015, p.71. Disponível em: $<$ http://www.teses.usp.br/teses/disponiveis/2/2135/tde-08042016-155605/pt-br.php> Acesso em : 25 de setembro de 2017.

${ }^{46}$ MIRRA, Álvaro Luiz Valery. "A questão dos "refugiados" climáticos e ambientais no Direito Ambiental." Conjur. Disponível em: < https://www.conjur.com.br/2017-abr-22/ambientejuridico-questao-refugiados-climaticos-ambientais-direito-ambiental $>$ Acesso em: 30 de out. de 2017.

${ }^{47}$ PROJET DE CONVENTION RELATIVE AU STATUT INTERNATIONAL DES DÉPLACÉS ENVIRONNEMENTAUX*. Disponível em: <http://www.observatorioeco.com.br/wpcontent/uploads/up/2010/09/projet-de-convention-relative-au-statut-international-des-daplacasenvironnementaux2.pdf>.Acesso em: 30 de out. de 2017 
De acordo com a autora é importante o reconhecimento e categorização dessas pessoas, tendo em vista que são migrantes em condições de vulnerabilidade, o que gera a necessidade de garantia de direitos e obrigações, principalmente por parte dos Estados. Contudo, há de se destacar que enquanto não há essa categorização, outros meios gerais de garantias de direitos não devem ser desconsiderados.

Nesse sentido, destaca que apesar de não haver proteção específica em âmbito internacional, no intento de garantir o gozo e o exercício dos direitos da pessoa humana, é preciso considerar a complementariedade da proteção existente no direito internacional geral através de outros mecanismos como o Direito Internacional dos Direitos Humanos, o Direito internacional dos refugiados, o Direito internacional Humanitário, o Direito Internacional das migrações, o Direito Internacional do Meio Ambiente, o Direito internacional das Mudanças Climáticas e o Direito dos Desastres Ambientais, como uma forma alternativa de proteção diante do hiato existente. ${ }^{48}$

Nessa perspectiva, Erika Ramos pontua que os migrantes por motivos ambientais precisam de um regime internacional de proteção, pois apenas lhes é oferecida uma proteção jurídica reflexa. ${ }^{49}$

A despeito da existência de outros meios distintos de proteção, ainda assim se faz necessário pensar em uma tutela específica a esse grupo de pessoas, levandose em conta suas peculiaridades e garantindo, assim, maior amparo jurídico.

Ramos ${ }^{50}$ ressalta que essa categoria continua em situação de indefinição jurídica, pois não se beneficiam da proteção definida pelo regime convencional existente e também não há um regime internacional de proteção específico para pessoas nessa condição.

Norman Myers, por sua vez, chama a atenção para o fato de que o reconhecimento dessa categoria pode voltar a atenção ao número de pessoas que sofrem com essa questão e, consequentemente, a uma análise e preocupação maior com os danos causados ao meio ambiente..$^{51}$

48 CLARO, Carolina. "A proteção dos "Refugiados Ambientais" no Direito Internacional." Faculdade de Direito da Universidade de São Paulo. 2015, p.87. Disponível em: $<$ http://www.teses.usp.br/teses/disponiveis/2/2135/tde-08042016-155605/pt-br.php> Acesso em : 25 de setembro de 2017.

${ }^{49}$ RAMOS, Erika Pires. "Refugiados Ambientais: em Busca de Reconhecimento pelo Direito Internacional." Faculdade de Direito da Universidade de São Paulo. 2011, p. 70. Disponível em: < http://www.teses.usp.br/teses/disponiveis/2/2135/tde-10082012-162021/pt-br.php> Acesso em: 29 de setembro de 2017.

${ }^{50}$ Idem.

51 MYERS, Norman. Environmental refugees: an emergent security issue. 2005, p.3. Disponível em: $<$ http://www.osce.org/eea/14851?download=true> Acesso em: 02 de maio de 2017. 
O referido autor analisa o refúgio ambiental como uma questão de segurança, pois, embora derive principalmente por problemas ambientais, gera inúmeros problemas de caráter político, econômico e social nos países que recebem essas pessoas. Com isso, poderia facilmente se tornar uma causa de turbulência e confronto, levando a conflitos e violência.

Nessa lógica, o Painel Intergovernamental sobre Mudanças Climáticas, o Conselho Consultivo de Ciências da ONU, projeta um aumento no número de deslocados ao longo deste século.

De acordo com o IPCC, as mudanças climáticas irão forçar as pessoas ao deslocamento, aumentar a pobreza e majorar os fatores que levam ao conflito, tornando ainda mais complexas as necessidades humanitárias e as respostas nessas circunstâncias. ${ }^{52}$

Diante de situações semelhantes às narradas acima, Myers defende a necessidade de políticas preventivas a necessidade de migrar e, para isso, a questão do meio ambiente não deve ser ignorada. De igual modo não devem ser negligenciados os refugiados ambientais pelo fato de não existir uma forma institucionalizada de lidar com eles.

O surgimento deste meio formal, principalmente pelo reconhecimento como categoria de refugiados ocasionará algumas consequências. A primeira, conforme acentua Claro, os deslocados ambientais por não estarem incluídos no rol da ONU de refugiados, não contam com a proteção que este instituto pode conferir, como por exemplo, a garantia de não devolução por parte do Estado que o recebeu, o já mencionado princípio do non refoulement. ${ }^{53}$

Nesta esteira, os Estados não podem impedir a entrada de refugiados, mas de estrangeiros comuns, o que torna os deslocados ambientais ainda mais frágeis, dada essa discricionariedade existente por parte do Estado. Isto posto, é possível inferir que o reconhecimento dessa categoria proporcionará meios mais efetivos de assistência, pois haverá uma vinculação do Estado em prestá-la.

Em contrapartida, Myers ${ }^{54}$ chama a atenção para o fato de que países desenvolvidos não tem demonstrado satisfação com o grande fluxo de migrantes e muitos desses já têm tomado medidas de restrição. Neste sentido, o

52 UNHCR. Environment, Disasters and Climate Change. Disponível em: < http://www.unhcr.org/environment-disasters-and-climate-change.html>. Acesso em: 25 de setembro de 2017.

53 CLARO, Carolina. "A proteção dos "Refugiados Ambientais" no Direito Internacional." Faculdade de Direito da Universidade de São Paulo. 2015, p.123. Disponível em: $<$ http://www.teses.usp.br/teses/disponiveis/2/2135/tde-08042016-155605/pt-br.php> Acesso em 25 de setembro de 2017.

${ }^{54}$ MYERS. Environmental Refugees: an Emergent Security Issue. 2005, p.3. Disponível em: < http://www.osce.org/eea/14851?download=true> Acesso em: 06 de out. de 2017. 
alargamento do conceito tradicional de refugiado proporcionaria aumento significativo das responsabilidades internacionais de várias nações, o que não é visto de forma positiva por muitas dessas.

Com isso, se por um lado existe a demanda de um grupo que carece de amparo jurídico específico, por outro existem Estados e populações que precisam se adequar a essa realidade.

Em outras palavras, o reconhecimento do refúgio ambiental trará diversas consequências, tanto para aqueles que precisam dessa proteção, como para os Estados que precisarão se adaptar para receber mais esse contingente de pessoas. Tal circunstância pode causar resistência em alguns países em aderir a formalização da categoria aqui tratada.

Ademais, imperioso mencionar que por meio da formalização desse grupo, será possível realizar melhor controle de quantas pessoas são forçadas a mudar por essa causa. Esses números ajudarão a compreender as proporções que essa modalidade de refúgio vem tomando. A partir disso, será possível demonstrar à comunidade global a necessidade de aplicação dos tratados de proteção ambiental.

No que se refere as consequências para os países, outro ponto importante que se revela dessa formalização é a questão da responsabilidade dos Estados. De acordo com Andrade e Angelucc ${ }^{55}$, o direito internacional tem revisto a questão da responsabilidade civil dos Estados. Não se pode olvidar que este instituto versa sobre a obrigação de reparação de danos imputada a alguém em virtude de uma ação ou omissão.

Como mencionam os referidos autores, este instituto foi descuidado pela doutrina por não haver um poder central global, fato este que ocasiona dificuldades na imposição de eventuais obrigações de reparação ao Estado que sofreu o dano. Somado a isso, está o fato de que essa imposição afrontaria a soberania nacional do Estado.

Ocorre que nos dias atuais, percebe-se que determinadas situações, ainda que tenham acontecido dentro dos limites territoriais nacionais, ocasionam repercussões em nível global, não sendo razoável, portanto, permanecerem sob a absoluta discricionariedade estatal, tornando-se, por isso, passíveis de interferência pela comunidade internacional. Atendo-se a discussão no que se refere à responsabilidade objetiva, aquela na qual para sua configuração é necessário ato, dano e nexo causal, pode-se afirmar, que eventos lícitos, mas

${ }^{55}$ ANDRADE \& ANGELUCC. "Refugiados Ambientais: Mudanças Climáticas e Responsabilidade Internacional." Holos. 2016, p.190-194. Disponível em: < http://www2.ifrn.edu.br/ojs/index.php/HOLOS/article/view/4165/1523> Acesso em: 06 de out. de 2017. 
causadores de risco iminente e excepcional, como testes nucleares e poluição marítima por hidrocarbonetos, podem acarretar a responsabilização internacional do Estado.

Contudo, faz-se necessária expressa previsão em tratado, quanto a responsabilidade objetiva, sendo indispensável norma que impute a alguém a responsabilidade pelo dano, não obstante a licitude da conduta. Reside aí a importância da admissão da categoria de refugiado ambiental, pois se não há o reconhecimento, por meio de uma normativa, de um grupo que sofreu com as ações dos Estados no meio ambiente, difícil se torna imputar ao Estado e aplicar aos casos concretos a responsabilidade objetiva.

Ante o exposto, pode-se perceber que o reconhecimento internacional dos refugiados ambientais trará consequências para os Estados, que vão desde políticas públicas para recepcionar essas pessoas, até maior controle sobre a responsabilização pela intervenção no meio ambiente. Para a sociedade civil, que passará a saber como lidar e recepcionar esse novo contingente e, principalmente, para esse grupo de vulneráveis que se encontra no limbo jurídico e que a partir da formalização poderá contar com maior amparo legal.

\section{CONSIDERAÇÕES FINAIS}

O impacto das mudanças climáticas é uma das maiores preocupações da humanidade, sendo necessário essa tomada de consciência coletiva pautada na vida e no equilíbrio ecológico.

Buscou-se demonstrar neste artigo que a questão climática é um problema atual e urgente para se pensar e atuar no plano global, em especial de desenvolver um direito que contemple e crie dentro do sistema internacional mecanismos e soluções para o desenvolvimento, considerando o ecológico, social e econômico; neste particular, ganha destaque o novo Direito Internacional das Catástrofes.

As catástrofes ambientais, causadas em grande medida pela interferência humana no meio ambiente, a despeito de produzir diversos problemas em termos globais, enseja a ocorrência de grandes fluxos migratórios.

Esse grupo de pessoas que se vê forçado a se deslocar, em razão de questões relacionadas ao meio ambiente, notadamente pelas mudanças climáticas, são aqui denominados refugiados ambientais, embora não haja o reconhecimento formal no plano normativo.

Com efeito, muito tem se debatido na doutrina quanto a melhor categorização, tendo em vista as consequências que decorrerão desse status. Como visto neste estudo, há aqueles que defendem a inclusão no rol estabelecido pela ONU, assim como também há aqueles que sustentam a 
necessidade de existência de uma nova categoria, independente da Convenção de 1951. Fato é que existem pessoas que se encontram em um "limbo jurídico" e que precisam do tratamento adequado para atender suas demandas.

Imperioso ampliar o rol de refugiados na Convenção da ONU ou o desenvolvimento de nova normativa que reconheça a categoria específica aqui tratada, para que haja tutela internacional mais sólida e efetiva para este grupo.

\section{REFERÊNCIAS BIBLIOGRÁFICAS}

AGENDA 2030. Os 17 Objetivos de Desenvolvimento Sustentável. Disponível em:

http://www.agenda2030.org.br/ods/13/

CENTER FOR DISASTER PHILANTHROPY. Disaster versus Catastrophes: The Difference Matter. Tanya Gulliver-Garcia. Octuber, 2019. Disponível em: https://disasterphilanthropy.org/blog/hurricanes-typhoons/disasters-versuscatastrophes-the-difference-matters/

DW. COM. Inundações na Alemanha: Antes e depois da catástrofe. Julho. 2021. Disponível em:

https://www.dw.com/pt-002/inunda\%C3\%A7\%C3\%B5es-na-alemanha-antes-edepois-da-cat $\%$ C3\%A1strofe/a-58319862

GUERRA, Sidney. Direito Internacional das Catástrofes. Curitiba. Editora Instituto Memória, 2021.

GUERRA, Sidney. Direito internacional ambiental. Rio de Janeiro: Freitas Bastos, 2006.

GUERRA, Sidney. GUERRA, Sérgio. Curso de Direito Ambiental. 2.ed. São Paulo: Atlas, 2014.

GUERRA, Sidney. Curso de Direito Internacional Público. 13.ed. São Paulo: Saraiva Educação, 2021.

GUERRA, Sidney. Direito das Organizações Internacionais. 2. Ed. Curitiba: Instituto Memória, 2020.

GULLIVER-GARCIA, Tanya. Disasters versus Catastrophes: The Difference Matters. Center for Disaster Philanthropy, p. 1-7, 8 out. 2019. Disponível em: 
https://disasterphilanthropy.org/blog/hurricanes-typhoons/disasters-versuscatastrophes-the-difference-matters/

ITAMARY. Transformando Nosso Mundo: A Agenda 2030 para o

Desenvolvimento Sustentável. 2015. Disponível em:

http://www.itamaraty.gov.br/images/ed_desenvsust/Agenda2030-completosite.pdf

NACIONES UNIDAS. Human Cost of Disasters: An overview of the last 20 years: 2000-2019. United Nations Office for Disaster Risk Reduction. Octuber 2020. Disponível em:

https://dds.cepal.org/redesoc/publication?id=5361\#: :text=In\%20the\%20period $\% 20$ 2000\%20to,over\%20the\%20previous\%20twenty\%20years.

PORTELA, Antônio José Santiago. As catástrofes: capacidade e vontade de encontrar soluções. Lusíada. Economia \& Empresa., Lisboa, n. 11, 2010.

Disponível em:

http://revistas.lis.ulusiada.pt/index.php/lee/article/view/879/956

UNITED NATION. Draft Articles on the protection of persons in the event of disasters. 2016. Disponível em:

https://legal.un.org/ilc/texts/instruments/english/draft_articles/6_3_2016.pdf

MCADAM, Jane; PRYKE, Jonathan. Mudança Climática, Desastres e

Mobilidade: Um Roteiro para a Ação Australiana. 2020, p. 8 Disponível em: https://www.kaldorcentre.unsw.edu.au/publication/podcast-climate-changedisasters-and-mobility-roadmap-australian-action.

NICK, FRAME. David. ALLEN. Climate change and global risk. In: Global Catastophic Risks. BOSTROM, Nick; ĆIRKOVIĆ (Org.) Orford. New York: Orford University Press. 2008.

POSNER, Richard. Catastrophe: risk and response. Oxford. University Press, USA, 2004.

WEISS, E.B. Climate chance, intergenerational equity and international law. Vermont Journal Environmental Law. 2008. 
WORLD METEOROLOGICAL ORGANIZATION. 2021 is "Make or break year" for Climate Action" Disponível em:

https://public.wmo.int/en/media/news/2021-\%E2\%80\%9Cmake-or-breakyear $\%$ E2\%80\%9D-climate-action

WORLD METEOROLOGICAL ORGANIZATION. State of the Global Climate 2020. 2021. Disponível em:

https://library.wmo.int/doc_num.php?explnum_id=10618 